\title{
Analysis of the Safety Level of Obstacle Detection in Autonomous Railway Vehicles
}

\section{Slobodan Rosić1 ${ }^{\text {, Dušan Stamenković }}{ }^{\text {, Milan Banić }}{ }^{1}$, Miloš Simonović $^{1}$, Danijela Ristić-Durrant ${ }^{2}$, Cristian Ulianov ${ }^{3}$}

\author{
${ }^{1}$ University of Niš, Faculty of Mechanical Engineering \\ Aleksandra Medvedeva 14, 18106, Niš, Serbia \\ slobodan.rosic@masfak.ni.ac.rs,dusan.stamenkovic@masfak.ni.ac.rs, \\ milan.banic@masfak.ni.ac.rs, milos.simonovic@masfak.ni.ac.rs \\ ${ }^{2}$ Institute of Automation, University of Bremen \\ Otto-Hahn-Allee NW1, 28359 Bremen, Germany \\ ristic@iat.uni-bremen.de \\ ${ }^{3}$ School of Engineering, Newcastle University \\ NE1 7RU, Newcastle upon Tyne, the UK; \\ cristian.ulianov@newcastle.ac.uk
}

\begin{abstract}
Traffic safety of fully automated train operations is one of the most complex challenges in the field of railway traffic automation. One of the biggest problems with the introduction of driverless trains to the public railway infrastructure are the risks associated with the obstacles on the line, which represent one of the most common and most significant safety risks in railway traffic. The Obstacle Detection System (ODS), should meet the safety requirements, but also should not lead to a deterioration of the railway traffic. In addition to the purely technical issues of ODS development, the issue of determining the necessary requirements in terms of safety, reliability and efficiency must be considered. The paper analyses the current European regulations in the field of railway safety, safety requirements for certification of ODS, as well as risk control measures by the types of obstacles on the line. A survey of train drivers in the Republic of Serbia was conducted to understand the significance of particular obstacles and the manner of reaction of train drivers in case of their occurrence. The results of the survey and the available statistical indicators were used to assess the impact of certain categories of obstacles on railway safety. The criteria for defining the safety requirements necessary for the certification of ODS in autonomous vehicles have been proposed.
\end{abstract}




\section{Introduction}

One of the main goals of modern railway transport is to increase its quality, as well its effectiveness and capacity while maintaining a very high level of safety [1] through automation. Automation is currently one of the most important trends in the railway development in order to oppose the strong competence of other transport means [2] and reduce Greenhouse Gas emissions [3], thus reaching the goals of the Green Deal. It is considered that, after electrification and the introduction of high-speed trains, it represents the third revolution in the development of railway traffic. This is one of the most complex areas in the field of automation. While other components in the process of automatic train operation (ATO) have already been successfully developed (automatic train control, optimal energy consumption, automatic door control and departure from station, etc.) train operation without a driver, the so-called Grade of Automation (GoA) level 4 has so far been successfully developed only for systems in specific environments (metro systems and mining lines in uninhabited areas). One of the biggest problems for the introduction of driverless trains on the public railway infrastructure are the risks associated with the obstacles on the line. Obstacles on the line represent the most common and most significant safety risk in railway traffic. Accidents caused by obstacles on the line account for over $83 \%$ of all significant accidents on European railways, and the casualties in such accidents make up over $99 \%$ of the total number of casualties in railway traffic. Almost 1,000 people die in such accidents on the EU railways every year. Obstacles on the railway also cause significant material damage [4]. Even insignificant obstacles such as fallen leaves on the track can have a significant negative impact - according to some estimates, the negative financial impact of this phenomenon on the railway system in the UK reaches up to 350 million pounds [5] and 100 million SEK in Sweden [6]. Obstacles on the line, including the implementation of the procedures associated with such events are significant cause of traffic delays and increased costs in the railway system. For this reason, it is necessary that the obstacle detection system (ODS) in the driverless train operation (DTO) regime successfully meets the requirements in terms of safety, but also not to lead to a deterioration in the efficiency and economy of railway traffic. Therefore, in addition to purely technical issues of development of these systems, it is also crucial to determine the necessary requirements for them in terms of safety, reliability and efficiency. The issue of defining the requirements for the ODS within the DTO is related to the regulatory conditions for their certification or authorization. It is very specific because according to the current regulatory framework in the EU, the area of detection and response to obstacles belongs to both structural and functional subsystems, and their introduction undoubtedly represents a significant change of both technical and operational character. Existing specifications and national regulations currently do not cover on board obstacle detection devices, so the conditions for their certification need to be defined in accordance with the EU regulatory framework. Alternative to ODS 
would be complete fencing of the railway lines which is not considered feasible by most EU infrastructure managers as the installation cost would be quite high. Furthermore, the current practical experience shows that fences cannot fully prevent occurrence of obstacles on the track [7].

Previous research in this area is mainly related to the technical aspect of the development of obstacle detection devices and the possibility of their application on railways. The authors $[1,8,9]$ provide an overview of the different types of sensors that can be used to detect obstacles and the possibility of using them for DTO. Hyde et al. [10] discusses the concept of an ODS and an overview of possible Use cases. Several researchers [11-13] are considering the use of neural networks in the field of detection of obstacles in railway traffic. The area of defining safety requirements for ODS has not been the subject of special research so far. This issue is being addressed as part of the SMART 2 [14] project which considers on board and track side ODS. At the end of 2020, the German Centre for Rail Traffic Research (DZSF) launched a study to define the requirements for authorizing the automated train operation [15]. The main goal of this study is to identify the requirements that must be met to ensure that automated trains provide at least the same level of safety as manually operated trains. There are still no academic papers on this topic, however, there are several papers [16, 17] that consider the problem of certification of signalling devices in which neural networks and artificial intelligence would be applied or discuss the safety evaluation by noted technologies [18].

This paper analyses the current European regulations in the field of railway safety, safety requirements for certification of obstacle detection devices, risk control measures by types of obstacles and proposes criteria for defining safety requirements that would be needed for certification of ODS in autonomous railway vehicles.

\section{Regulatory Requirements that the ODS should Meet and the Manner of Their Certification in Accordance with EU Legislation}

The European regulatory framework for railways is very complex due to the required interoperability and open market for railway services. According to this framework, the railway system is divided into structural and functional subsystems and implies the participation of a large number of actors like railway companies, independent bodies, national state bodies and European institutions.

The area of certification is largely defined by Directive 2016/797 on the interoperability of the railway system in the EU [19]. This directive prescribes requirements for all the parts of the railway system as well as a way of proving 
their fulfillment. The basic elements of the certification process according to this document are sublimated in a form diagram presented as Figure 1.

The Interoperability Directive defines a number of general and specific safety requirements. Relevant to the development of a system for the detection of obstacles are the following:

- General requirements

a) The ODS must be designed and constructed to guarantee safety at the level corresponding to the aims (goals) laid down for the network.

b) The components of the ODS must withstand all specified normal or exceptional stresses during their use. Impact of accidental failures on the safety must be limited.

c) The design of ODS must be aimed at limiting the negative consequences of a fire.

d) The supervision and maintenance of the ODS must be organized, carried out and quantified in such a manner that their operation is carried out under the intended conditions.

\section{Requirements Defining}

-High level - essential requirements that EU rail system, subsystems and constituents and interfaces shall meet. This requirements are defined in Annex III Directive 2016/797

- Technical specification for interoperability' (TSI) which define the technical and operational standards which must be met to satisfy the 'essential requirements' and to ensure the interoperability. TSIs are defined for each subsystem

- National rules which defining the requirements for so-called open issues and special cases in TSIs

\begin{tabular}{l} 
Demonstration of compliance with the requirements \\
- Conformity assesment with TSIs and national rules acording Article 13 Directive \\
$2016 / 797$ \\
-Verification of conformiti assesment \\
\hline Authorisation for the placing in service \\
•Proving verification declaration \\
•Proving technical compatibility \\
•Proving safe integration \\
•Proving procedure is carried out acording Article 18 Directive 2016/797
\end{tabular}

Figure 1

Basic elements of the certification process in accordance with EU regulations

- Specific requirements

The ODS and interface with control-command and signalling (CCS) installations and procedures used must enable trains to travel with a level of safety which corresponds to the objectives set for the network. This system must continue to ensure the safe passage of trains which are allowed to run in degraded conditions (failures in CCS system). 
The first-mentioned general requirement and the specific requirement for CCS systems are virtually identical. This practically means that the introduction of an ODS must ensure a level of safety that corresponds to the objectives envisioned for the railway network. The Safety Directive EU 2016/798 [20] states that the basic objective for the railway network in the EU is to preserve the existing level of safety. Article 7 of the same Directive also defines the Common Safety Targets (CST) as the minimum levels of safety that the system as a whole and its various parts need to achieve. CSTs can be expressed in risk acceptance criteria or target safety levels. CSTs relevant to the ODS are aims related to train collisions with trains and obstacles on the line (within the clearance profile), for accidents at level crossings, for accidents involving people involving a moving railway vehicle and for passing a signal prohibiting further driving (SPAD). Although there are many doubts about the use of CST in the certification process, the study [21] states that for the development of new elements of the subsystem on the railway it is necessary to define individual, specific objectives based on the value of CST. When considering the method of their calculation [22], CSTs based on the level of safety achieved in the previous period. Therefore, these conditions practically assure reaching at least the existing level of safety in their areas.

Finally, safety objectives may exist at the level of a network and individual actors in the railway system (Infrastructure managers and Railway undertakings). Since these goals must be harmonized with the CST also, they are almost without exception based on the existing level of safety. Deviations from the achieved level of safety are possible only if this level is not satisfactory for an area. However, there is a constant improvement in safety in the EU railway system [4] and there are currently no strong arguments to justify raising safety levels as a condition for certification of obstacle detection devices. For the development and implementation of DTOs, these safety objectives imply that the level of safety required of the ODS must be at least equal to the level of safety achieved by the train driver in relation to line obstacles on the line. This can also be considered a basic high-level requirement in terms of the functional aspect of system safety. Other specified general and specific conditions relevant for the development and certification for ODS related to reliability, applicability, maintenance, and technical aspects of safety (RAMS). The requirements in this regard are mostly based on the EN 50126 Railway applications standard - The specification and demonstration of Reliability, Availability, Maintainability and Safety (RAMS) [23].

The second level of safety requirements is defined in the TSI. However, as such a system has not existed so far on the railways in the TSI CCS, to which by the nature of things ODS should belong, there are currently no requirements related to this system. This area is currently covered by TSI OPE. It defines safety requirements regarding the occurrence of hazards on the railway, which includes the occurrence of obstacles on the line. But these requirements are defined at a general level and mainly refer to national and internal regulations. A safety 
requirement to record and store all relevant vehicle control and operation data before and after an accident could be considered an explicit requirement for this system. Therefore, the existing TSIs need to be supplemented with provisions relating to the ODS. Interoperability Directive requires that all proposals for amendments to existing or new specifications within the TSI must be proven to meet the existing essential requirements. Similar to TSIs, national regulations currently do not have defined requirements for such a system. However, some requirements for it can be deduced from the operational rules for train drivers. They are mostly identical for all European countries, but there are also certain differences. For example, in Great Britain, it is prescribed that the train driver is obliged to take appropriate measures in case of noticing leaves on the tracks and to report it to the traffic control, which is not the case in many other countries [24]. There are also significant differences between European countries in terms of procedures in the case of the appearance of animals on the line.

In addition to the above safety requirements, European regulations stipulate that during the certification of subsystems and their elements, the safe integration into the existing railway system must be ensured [19]. Since the introduction of an ODS instead of a train driver is undoubtedly a change of great importance for the traffic safety, the fulfilment of this requirement implies the application of the Common safety methods for assessing the risk of changes in the railway system (CSM RA). Regarding the basic requirement of the functional aspects of safety, in CSM RA procedure, the principle of risk acceptance GAME (Globalement au moins équivalent) should be applied. From the recapitulation of the stated regulatory requirements for the certification of the ODS, it can be concluded that it must meet the following conditions:

1) The level of safety of this system in functional terms must correspond to the set objectives for the network, which practically means that the ODS must provide the least achieved general level of safety, and the achieved level of safety defined by individual CST. This requirement is an essential requirement for the development of this system. Based on this safety objectives, the necessary technical specifications should be further developed.

2) The Reliability, Availability, Maintainability and Safety (RAMS) requirements for the ODS should comply with the EN 50126 standard. For the technical aspect of safety, the requirements should be at least at the same Safety Integrity Level (SIL) level as for other onboard CCS devices [23].

3) The achievement of the existing level of safety as well as the acceptability of the risks associated with the introduction of an ODS in the existing railway system should be determined by applying the ZBM RA using the GAME principle of acceptability of risk. Deviations from this principle are possible only if an increase in the level of safety is explicitly required. 
4) The system must meet the requirements of national regulations regarding the occurrence of obstacles on the line at the same safety level as train drivers, and if that is not possible, other ways and measures of risk control must be defined and introduced.

\section{Analysis of the Existing Level of Safety in the Railway System Related to Obstacles on the Line}

The term existing or achieved level of safety is very important in the EU regulatory framework for the railway system and is stated in a number of legal documents. Its achievement in the case of change (including innovation) is a crucial safety requirement. It also has an important legal aspect because it represents the limit of what is legally allowed and what is not, in the railway system. But, despite the great importance of this term in the regulations, there is no defined way in which it is determined in the railway system. This problem is not considered in more detail in academic papers either. In practice, the existing level of safety is usually determined based on so-called "historical records" about accidents. However, common statistics do not provide enough information to adequately establish the achieved level of safety associated with railway barriers. The main reasons for this are:

- accident statistics cover only events that had harmful consequences. Most obstacle-related events end without such consequences, so the number of accidents alone does not give a true picture of the frequency of hazards.

- a number of accidents does not represent unsuccessful events from the aspect of reacting to the appearance of obstacles. These are events in which the train crash could not be avoided due to the circumstances, but the timely response resulted in the maximum possible reduction of the consequences of the crash.

- the classification of accidents is not detailed enough in terms of different types of obstacles, so it does not give a true picture of the degree of risk of individual categories of obstacles.

An analysis of the available safety data on European railways was performed, to adequately describe the existing level of safety. The main source of data are the safety reports issued at the EU level by the European Union Agency for Railway and for individual members by their National safety authority. This data is contained in the ERADIS database [25], which combines all the data relevant to the safety and interoperability on the European railways.

Analysis of the data from these reports for 2019 (the last year for which all the data are available) showed that collisions, which are in terms of possible consequences the most dangerous type of event, are very rare events. They make 
up only about $0.6 \%$ of the total number of accidents and the number of casualties in them is about $1 \%$ of the total number in all railway accidents in Europe. The vast majority of accidents related to obstacles, and casualties in them, are accidents at level crossings and unauthorized people crossing the track. On European railways, between 250 and 300 people are killed at level crossings every year, and over 600 people are killed by moving railway vehicles (without suicides). This relationship between the number of collisions, level crossings accidents and accidents with people and the consequences of these events is very similar in almost all European countries [25].

An analysis of the reports of all national safety authorities showed that the Danish National Safety Authority TBB has the best detailed information on the dangerous events related to obstacles. Their report includes data on serious accidents, minor accidents as well as other dangerous events (precursors) that include avoided collisions (near misses) with some types of obstacles.

As part of the research conducted during the SMART2 [14] project in 2020, a survey of train drivers in Serbia was conducted, to determine the existing level of safety. The survey included a total of 68 train drivers from three operators in Serbia (one incumbent and two private freight operators). The average work experience of the surveyed train drivers is 21.7 years. The survey included 3 categories of questions:

1) Questions about work experience: company name, the type of traffic it performs (international / domestic, cargo passenger, shunting, hazardous materials), years of service;

2) Questions about dangerous situations: types of dangerous situations the driver has experienced (collision with a railway vehicle, collision with an object with a description of the type of object, collision at a level crossing, collision with a person, collision with an animal, near-miss by the same categories, other dangerous situations with obstacles according to one's own description, the number of these events or the frequency (in each shift, monthly, annually, in several years) and the assessment of the hazard to the safety of the train or people and the environment that a certain type of event represents;

3) Questions about the risk control measures they take in individual cases and about the effects of those measures (most often consequences of individual types of events).

Table 1

Most important results of the survey of 68 train drivers in Serbia

\begin{tabular}{|l|c|c|}
\hline 1 Experience of train drivers & Number of drivers & Percentage \\
\hline all kinds of traffic & 51 & $75 \%$ \\
\hline passenger & 3 & $4,5 \%$ \\
\hline freight & 13 & $19 \%$ \\
\hline shunting & 1 & $1,5 \%$ \\
\hline
\end{tabular}




\begin{tabular}{|l|c|c|}
\hline $\begin{array}{l}\text { 2 The types of dangerous } \\
\text { events he has experienced }\end{array}$ & \multicolumn{1}{|c|}{$\begin{array}{c}\text { The number of train } \\
\text { drivers who had that } \\
\text { event }\end{array}$} & $\begin{array}{c}\text { The total number of } \\
\text { these events }\end{array}$ \\
\hline 2.1 Collision & 7 & 7 \\
\hline with train & 22 & 27 \\
\hline $\begin{array}{l}\text { with an object that endangers } \\
\text { the safety of the train }\end{array}$ & 49 & 69 \\
\hline on level crossing & 51 & $53^{* *}$ \\
\hline with person & 14 & 18 \\
\hline with big animal & 5 & 6 \\
\hline 2.2 Near miss & 41 & 54 \\
\hline with train & 67 & 217 \\
\hline $\begin{array}{l}\text { with an object that endangers } \\
\text { the safety of the train }\end{array}$ & 66 & $255^{*}$ \\
\hline on level crossing & 21 & 37 \\
\hline with person & \multicolumn{2}{|l}{} \\
\hline with big animal & \multicolumn{2}{|l|}{} \\
\hline
\end{tabular}

*the total number of events for all 68 surveyed train drivers (multiple events occurred) **this number also includes suicides that are not covered by safety reports

Drivers were asked to state the exact number of different types of dangerous events in which they participated, and if they could not, to state the approximate frequency of these events at the stated intervals. The vast majority of surveyed train drivers $(92.65 \%)$ stated the exact numbers of events only for collisions with a railway vehicle, collisions with a landslide and collisions with people. For other categories, approximate frequencies are generally given. For this reason, it was decided to use the data from the safety report of the Danish national safety authority as the main source for the frequency of events, and to use the data from the train driver survey as their supplement. Although there are some differences in the number of individual categories of dangerous events between Denmark and Serbia, the relationship between the total number of significant and minor accidents and precursors of dangerous events (including near-miss) is similar. The most important results of the train driver survey are shown in Table 1.

The data from the driver's survey was the basis for determining the classification of obstacles and determining the risk control measures that are applied in the event of the occurrence of a certain type of obstacles.

\subsection{Classification of Obstacles in the Railway System}

Any object (object or a living being) that is or can be found on the train's running path in clearance (free) profile and that can affect its normal movement can be considered an obstacle for the train. This means that in addition to the object in the clearance (free) profile of the railway, any object in the area next to the railway 
that is in the zone of the train stopping distance and can realistically be found on the train's running path is also considered an obstacle. The classification of the obstacles depending on the type and possible harmful effects as well as risk control measures applied in case of their occurrence is given in Table 2.

Table 2

Classification of the obstacles and risk control measures taken in case of their occurrence

\begin{tabular}{|c|c|c|}
\hline Type of the obstacle & Risk control measures taken & Severity \\
\hline \multicolumn{3}{|c|}{$\begin{array}{l}1 \text { Immovable objects in the free profile of the railway line } \\
\text { stones / earth, railway vehicles, parts of railway equipment, vegetation, liquids, } \\
\text { construction material, packaging, etc. accidentally or intentionally left on the tracks. A } \\
\text { signal that prohibits further driving can also be considered in this class of obstacles. }\end{array}$} \\
\hline $\begin{array}{l}\text { 1.1 Immovable objects which, } \\
\text { due to their dimensions and } \\
\text { physical characteristics, do not } \\
\text { endanger the safe movement of } \\
\text { the train and cannot cause } \\
\text { harmful consequences } \\
\text { packaging, small items, thin } \\
\text { branches }\end{array}$ & $\begin{array}{l}\text { It is not necessary to take risk } \\
\text { control measures, i.e., the } \\
\text { usual way of driving the train } \\
\text { does not change. }\end{array}$ & No consequences \\
\hline $\begin{array}{l}\text { 1.2 Immovable objects that do } \\
\text { not endanger the safe } \\
\text { movement of the train but may } \\
\text { cause minor damage to } \\
\text { vehicles or traffic disturbances } \\
\text { thick branches, leaves, deeper } \\
\text { liquid, parts of railway } \\
\text { equipment }\end{array}$ & $\begin{array}{l}\text { reduction of train speed, if } \\
\text { necessary, until stopping but } \\
\text { without emergency braking, } \\
\text { activation of anti-slip devices, } \\
\text { notifying the control centre of } \\
\text { an obstacle on the track }\end{array}$ & $\begin{array}{l}\text { Material damage, traffic } \\
\text { disruption } \\
\text { Only indirect safety } \\
\text { consequences are } \\
\text { possible (in case another } \\
\text { irregularity in the system } \\
\text { occurs at the same time) }\end{array}$ \\
\hline $\begin{array}{l}1.3 \text { Immovable objects that } \\
\text { endanger the safe movement of } \\
\text { trains } \\
\text { railway vehicles, larger } \\
\text { deposits of earth/stones, } \\
\text { construction materials }\end{array}$ & $\begin{array}{l}\text { imperative stopping of a train } \\
\text { in front of an obstacle, if the } \\
\text { distance to the obstacle } \\
\text { requires it with the } \\
\text { introduction of emergency } \\
\text { braking, informing the control } \\
\text { centre about the obstacle on } \\
\text { the line }\end{array}$ & $\begin{array}{l}\text { Catastrophic } \\
\text { consequences in the } \\
\text { railway system }\end{array}$ \\
\hline \multicolumn{3}{|c|}{$\begin{array}{l}2 \text { Movable objects in the free profile of the railway } \\
\text { animals, people, vehicles }\end{array}$} \\
\hline $\begin{array}{l}\text { 2.1 Movable objects that do } \\
\text { not endanger the safe } \\
\text { movement of the train but the } \\
\text { consequences for them can be } \\
\text { fatal } \\
\text { small and medium-sized } \\
\text { animals, people, light vehicles }\end{array}$ & $\begin{array}{l}\text { activation of warning signals } \\
\text { (sound and light) and possible } \\
\text { reduction of train speed; } \\
\text { in case the person cannot } \\
\text { safely leave the free profile } \\
\text { stopping of train }\end{array}$ & $\begin{array}{l}\text { Minor material damage; } \\
\text { Victims outside the } \\
\text { railway system (third } \\
\text { parties, human } \\
\text { environment) }\end{array}$ \\
\hline
\end{tabular}




\begin{tabular}{|c|c|c|}
\hline Type of the obstacle & Risk control measures taken & Severity \\
\hline $\begin{array}{l}2.2 \text { Movable objects that } \\
\text { endanger the safe movement of } \\
\text { trains } \\
\text { large animals, heavy vehicles }\end{array}$ & $\begin{array}{l}\text { activation of warning signals } \\
\text { (sound and light) and } \\
\text { reduction of train speed; in } \\
\text { case the object cannot safely } \\
\text { leave the free profile stopping } \\
\text { the train, in case of heavy } \\
\text { vehicles possible emergency } \\
\text { braking }\end{array}$ & $\begin{array}{l}\text { Significant consequences } \\
\text { in the railway system; } \\
\text { Victims outside the } \\
\text { railway system (third } \\
\text { parties, human } \\
\text { environment) }\end{array}$ \\
\hline $\begin{array}{l}3 \text { Immovable objects in the } \\
\text { immediate vicinity of the } \\
\text { railway that may endanger the } \\
\text { free profile and endanger the } \\
\text { safety of the train } \\
\text { damaged catenary equipment, } \\
\text { damaged buildings and } \\
\text { vegetation, running water, } \\
\text { unstable soil and rock masses }\end{array}$ & $\begin{array}{l}\text { notifying the control centre } \\
\text { and possibly acting on its } \\
\text { order }\end{array}$ & $\begin{array}{l}\text { Only } r \text { indirect } \\
\text { consequences for safety } \\
\text { are possible. These } \\
\text { consequences can be } \\
\text { significant }\end{array}$ \\
\hline \multicolumn{3}{|c|}{$\begin{array}{l}4 \text { Movable objects in the immediate vicinity of the line that can enter in the free profile } \\
\text { animals, people, road vehicles }\end{array}$} \\
\hline $\begin{array}{l}\text { 4.1 Movable objects in the } \\
\text { immediate vicinity that cannot } \\
\text { endanger the safe movement of } \\
\text { the train, but the consequences } \\
\text { for them can be fatal } \\
\text { small and medium-sized } \\
\text { animals, people, light vehicles }\end{array}$ & $\begin{array}{l}\text { activation of warning signals } \\
\text { (sound and light); in case the } \\
\text { object continues to move } \\
\text { towards the free profile, } \\
\text { reducing of the speed and, if } \\
\text { necessary, stopping the train }\end{array}$ & $\begin{array}{l}\text { Minor material damage; } \\
\text { Victims outside the } \\
\text { railway system (third } \\
\text { parties, } \\
\text { environment) }\end{array}$ \\
\hline $\begin{array}{l}4.2 \text { Movable objects in the } \\
\text { immediate vicinity that } \\
\text { endanger the safe movement of } \\
\text { trains } \\
\text { large animals, road vehicles }\end{array}$ & $\begin{array}{l}\text { activation of warning signals } \\
\text { (sound and light); in case the } \\
\text { object continues to move } \\
\text { towards the free profile, } \\
\text { reducing the speed and, if } \\
\text { necessary, stopping the train, } \\
\text { in the case of heavy vehicles } \\
\text { possible emergency braking }\end{array}$ & $\begin{array}{l}\text { Significant consequences } \\
\text { in the railway system; } \\
\text { Victims outside the } \\
\text { railway system (third } \\
\text { parties, } \\
\text { environment) }\end{array}$ \\
\hline
\end{tabular}

\subsection{Determining the Frequency of Occurrence of Different Categories of Obstacles}

As in other European countries, dangerous events on the Danish railways are divided into serious accidents, minor accidents, and incident precursors [26].

According to the 2019 Railway Safety Report, there were a total of 13 serious accidents related to railway obstacles in Denmark, 5 less than in the previous year. The number of accidents related to obstacles that are categorized as minor in 2019 was 186 in Denmark, 28 more than in the previous year. Their distribution is shown in Figure 2. 
Although the division of events in these reports does not fully correspond to the categories of obstacles listed in Table 2, we can consider that the data on serious collisions with railway vehicles and facilities is relevant for the category of obstacles "1.3. Immovable objects that endanger the safe movement of trains". Data on accidents at level crossings is relevant for the category "2.2 Movable objects that endanger the safe movement of trains", and data on collisions with people is relevant for category "2.1 Movable objects that do not endanger the safe movement of the train, but the consequences for them can be fatal".

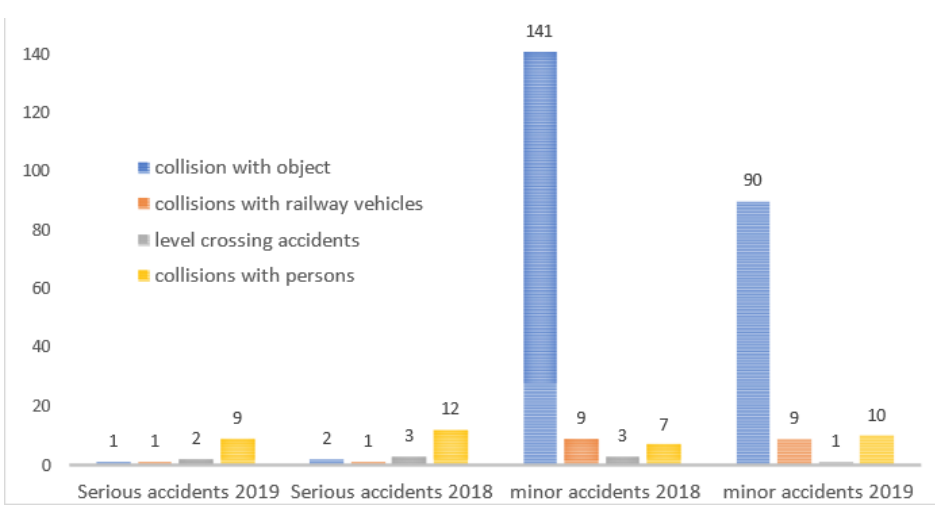

Figure 2

The number of serious and minor accidents related to obstacles on the Danish Railways

Data on collisions with people, accidents at level crossings and collisions with railway vehicles is relevant for the same categories of obstacles as in the case of serious accidents. Collisions with objects that are categorized as minor accidents according to the mentioned safety report are mainly collisions with larger animals (horses, cows, deer), felled trees, smaller objects and pieces of equipment. There is no more detailed division of these events, but it is estimated that about half of these events are smaller objects and that this is a relevant parameter for the category of obstacles "1.2 Stationary objects that do not endanger safe train movement but can cause minor damage to vehicles or traffic disturbances". The other half of these events are considered to be collisions with larger animals and this number is relevant for category "2.2 Movable objects that endanger the safe movement of trains ".

The largest number of dangerous events is in the precursors. Precursors relevant to the hazard of obstacles are Risky events with people and Risky events at level crossings. In Denmark, over 1,200 such events related to obstacles were recorded in 2019, about 200 such events more than in 2018.

Risky events with people and at level crossings are mostly events in which the train could have hit a person or a vehicle, but it was avoided, the so-called nearmiss. Risky events with people are relevant for category "4.1 Movable objects in 
the immediate vicinity that cannot endanger the safe movement of the train, but the consequences can be fatal", and risky events for category "4.2 Movable objects in the immediate environment that endanger the safe movement of trains".

\subsection{Assessment of the Impact of Certain Categories of Obstacles on Railway Safety}

From the available data in the report of the Danish National Safety Authority, data for category "1.1 Immovable objects that cannot endanger train" safety cannot be extracted. To understand the significance of certain obstacles and the manner of reaction of train drivers in case of their occurrence, data from the survey of train drivers was used. From it can be concluded that this is an everyday occurrence. The most common objects from that category are smaller pieces of vegetation, empty boxes, and smaller stones, but some unusual objects such as, e.g., snowman on the track were also recorded. Since this category of obstacles has no impact on safety, it is not necessary to quantify it for the process of defining safety requirements.

This is also the case for the obstacles from category " 3 Immovable objects in the immediate vicinity of the railway line that may endanger the free profile and endanger the safety of the train". The relevant Safety Reports do not provide appropriate data for their quantification, but this category of obstacles does not have a direct impact on the safety of the train that detects these obstacles, so its quantification is not necessary within the procedure for defining safety requirements. However, in the risk assessment process related to the safe integration of the ODS into the existing railway system, it is necessary to determine the capabilities of this system for the detection of this type of obstacle and informing the control centre about them. In case that this cannot be at the level that the train drivers have (which is to be expected), it is necessary to consider other ways of controlling these risks. For example, if the ODS is not able to successfully detect the appearance of wet leaves on the track, information from the adhesion control sensor or anti-slip protection can serve as a risk control measure.

The data from the Danish report is incomplete for category "4.2 Movable objects in the immediate vicinity of the line that endanger the safe movement of trains" because they do not include risky events with large animals, i.e. near-miss. This type of incident is not covered by safety reports in any European country, so that number was estimated on the basis of a survey conducted in Serbia. According to the survey, the number of near misses with large animals is twice the number of collisions with them, so according to that key, the number of these events can be determined.

Based on the analysis of the frequency and possible consequences of certain categories of obstacles to railway safety, the following can be concluded: 
- Collisions with immovable obstacles from category 1.3 , which represents the greatest hazard in terms of possible consequences, are very rare events. Risk control measures within other parts of the railway system obviously control these risks at a very high-level. However, the ODS must be able to detect such objects in a timely manner to avoid them or at least reduce the harmful consequences. The system must be able to correctly classify objects from this category of events because incorrect classification can cause unnecessary safety risks (unnecessary emergency braking) or reduce the efficiency of the railway system (stopping in front of an obstacle when it was not necessary).

- The largest number of events refers to moving obstacles and over $93 \%$ of these events refer to avoided collisions with them. From the aspect of individual and social risk, these obstacles represent by far the greatest risk in the railway system. Primary safety requirement is the condition that the ODS must not exceed the level of risk that exists with train drivers in the case of moving obstacles. In the category of moving obstacles, the largest number of these events is from category 4.1 and they individually represent the highest risk. The system must be able to detect these obstacles, initiate the activation of the warning signal and then monitor the movement of the obstacle, i.e. whether it passes into category 2.1 or ceases to be an obstacle. The system must be able to correctly classify objects from this category of events because incorrect classification can cause additional safety hazards (occurrence of a much larger number of obstacles in category 2) or reduction of railway system efficiency (stopping in front of an obstacle when it was not necessary).

- In the case of the obstacles that do not have a direct impact on the railway safety and do not cause harmful consequences outside the railway system (category 3 and partially 1.2), the ODS does not need to fully detect them. But in the process of risk assessment, it is necessary to establish other risk control measures that will replace the measures implemented by the driver in such cases.

\section{Requirements for the ODS based on the Assessment of the Impact of Obstacles on Railway Safety}

The need for proper classification of obstacles and monitoring the movement of moving obstacles places high demands on the ODS. The application of the traditional safe-side principle on the railway (to treat everything as the worst case) for the ODS in DTO mode has certain limitations. The worst case involves emergency braking that can cause the train to derail [27]. In addition, the absolute application of the safe-side principle would mean that the train should be stopped in case of any detected obstacle, which would, given the large number of events 
that do not pose a danger or pose only a potential safety hazard (obstacle categories 1.1, 3, 4.1 and 4.2) significantly jeopardize the efficiency and economy of railway traffic. Especially having in mind that there are no staff on the train in the DTO mode. Carrying out the procedures after stopping the train would require far more time than in the case when the driver is on board.

For these reasons, it is necessary that the ODS can monitor and classify obstacles, at least at the level that the train drivers can achieve. This is not an easy task, especially in the case of moving obstacles. For successful classification of obstacles, it is necessary to determine several parameters, some of which are not easy to determine. Unlike road traffic, trains have very long stopping distances and this drastically increases the number of possible risk situations. Practically every living being or vehicle that is located at a distance of a kilometre or two (depending on the type of train) near the railway represents a potential danger that must be detected and assessed. Based on a survey with train drivers conducted in Serbia, it can be concluded that they assess the risk of moving obstacles based on distance, position of the obstacle in relation to the free profile, its movement, but also some characteristics of the obstacle itself. In case of humans this assessment can be based even on the so-called body language. At the same time, none of the parameters has an unambiguous influence on the risk assessment. In some cases, a more distant obstacle may be more risky than a closer one.

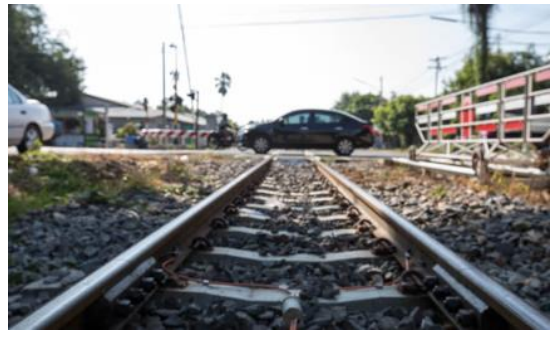

$\mathrm{a}$

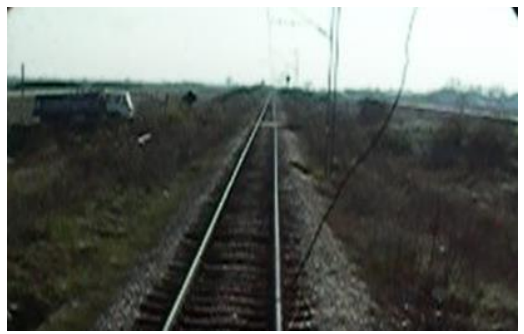

b

Figure 3

The vehicle in a free profile at the level crossing (a) and moving towards the level crossing at high speed (b)

For example train drivers will not assess a railway worker in a free profile, even at a very short distance, as a great hazard because they know that they are professionals, trained for such situations and medically fit to timely move from a free profile. Hence, in case of detecting a railway worker in a free profile, train drivers will not take any measures other than the warning sign. On the other hand, some categories of people (e. g., small children, people with special needs) will be considered a great risk, and drivers will start to brake even at a great distance. Also, in some cases, a moving obstacle outside the free profile at a greater distance will be considered as a higher risk than one that is in the free profile at a 
shorter distance. A vehicle that is in a free profile leaving the level crossing (Figure 3 a) will not be considered a big risk (except at a very short distance), while, on the other hand, a vehicle moving towards the level crossing at highspeed will be considered a big risk even at a greater distance (Figure $3 \mathrm{~b}$ ).

In addition to the movable obstacles, immovable ones also require classification based on the risks they pose to safety. For example, whether a cardboard box in the free profile of the track poses a significant risk depends on its size, position in the free profile and content. This issue is also greatly influenced by the type of the railway vehicle, because the risk of immovable obstacles is drastically different for, e.g. a heavy locomotive on freight trains and a light diesel motor train.

The need to classify and monitor obstacles obviously requires the application of advanced object detection and classification methods. In recent years, the advancement in neural network technology has enabled great improvement in object (obstacle) detection based on Artificial Inteligence (AI) in rail road traffic applications [8]. However, introduction of AI-based obstacle detection and classification can be a problem when meeting technical safety requirements. The usual approach to certifying CCS devices involves reaching the required SIL. However, certification of systems that contain AI for SIL 4 level can be problematic, some standards do not recommend the use of AI for systems where a level higher than SIL 1 is required [17]. Given the large number of possible obstacles in the railway system and the complexity of this issue, machine learning will be a long - term process that will require extensive experimental application of this system before starting the process of its certification. A rational approach to solving this problem would therefore be to introduce an AI-based ODS in ATO level 3 (attended train operation). Mass application of this system in that regime could enable adequate training of the AI system for the classification of obstacles and raising its level of safety to the level required to reach SIL 4. In addition, the acceleration of mass application would be supported by using of eXplainable Artificial Intelligence (XAI)-based object detection and classification as opposed to current primarily "black box" use of AI-based methods [28]. Namely, "black box" approaches usually cause uncertainty regarding the way they operate and, ultimately, the way that they come to decisions. This ambiguity is problematic for machine learning systems to be adopted in sensitive yet critical domains, such as obstacle detection in railway. XAI can explain how AI obtained a particular solution (e.g., classification or object detection) and can also answer other "wh" questions, such as "which object features dominated when making AI-based decision on object classification?". Using of XAI could increase trust in and transparency of an AI-based object detection and classification.

\section{Conclusions}

ODS are one of the basic conditions for the introduction of DTO. In the European regulatory framework, the condition that they must at least provide a level of safety in relation to the obstacles on the line that is achieved by train drivers, can 
be considered the basic safety requirement. This aspect is particularly important in the case of DTOs where the responsibility for accidents is shifted from the human control factor to the design and approval of the automatic control device.

Autonomously operated trains can increase the existing level of safety as they can lead to the elimination of human errors or improve the recognition of obstacles in difficult conditions. On the other hand, they can reduce that level in unexpected and more complex situations. They can also negatively affect the efficiency and economy of railway traffic.

To determine the achieved level of safety, the most important is the analysis of risks related to obstacles and the ways of their control by train drivers. It is therefore essential that the system must be able to classify all obstacles and monitor moving obstacles. This requires the application of an artificial intelligence system that is not easy to certify according to existing standards in the European railway system. One solution to this problem is the mass introduction of a detection system in ATO level 3 mode that should serve as a training phase for the system.

\section{Acknowledgement}

This research received funding from the Shift2Rail Joint Undertaking under the European Union's Horizon 2020 research and innovation program under Grant No. 881784.

\section{References}

[1] Banić, M., Miltenović, A., Pavlović, M. and Ćirić, I., (2019) Intelligent machine vision based railway infrastructure inspection and monitoring using UAV. Facta Universitatis, Series: Mechanical Engineering, 17(3), pp. 357-364

[2] Sysyn, M., Nabochenko, O., Kovalchuk, V., Przybyłowicz, M. and Fischer, S., (2021) Investigation of interlocking effect of crushed stone ballast during dynamic loading. Reports in Mechanical Engineering, 2(1), pp. 6576

[3] Petrović, N., Bojović, N., Petrović, M. and Jovanović, V., (2020) A Study of The Environmental Kuznets Curve For Transport Greenhouse Gas Emissions In The European Union. Facta Universitatis, Series: Mechanical Engineering, 18(3), pp. 513-524

[4] ERA, "Report on Railway Safety and Interoperability in the EU 2020", 2021

[5] RSSB, "Trial of Sander Configurations and Sand Laying Rates", T1107 Project Report, Issue 1, 2018

[6] Olofsson, U. and Sundvall, K., (2004) Influence of leaf, humidity and applied lubrication on friction in the wheel-rail contact: pin-on-disc 
experiments. Proceedings of the Institution of Mechanical Engineers, Part F: Journal of Rail and Rapid Transit, 218(3), pp. 235-242

[7] Rail Accident Report - Derailment at Godmersham, Kent on 26 July 2015. Report 05/2016. Rail Accident Investigation Branch, Department for Transport. April 2016

[8] Ristić-Durrant, D., Franke, M. and Michels, K., (2021) A review of visionbased on-board obstacle detection and distance estimation in railways. Sensors, 21(10), p. 3452

[9] Pavlović, M., Nikolić, V., Simonović, M., Mitrović, V. and Ćirić, I., (2019) Edge detection parameter optimization based on the genetic algorithm for rail track detection. Facta Universitatis, Series: Mechanical Engineering, 17(3), pp. 333-344

[10] Hyde, P., Ulianov, C., Liu, J., Banic, M., Simonovic, M. and RisticDurrant, D., (2021) Use cases for obstacle detection and track intrusion detection systems in the context of new generation of railway traffic management systems. Proceedings of the Institution of Mechanical Engineers, Part F: Journal of Rail and Rapid Transit, p. 09544097211041020

[11] Yu, M., Yang, P. and Wei, S., 2018, May. Railway obstacle detection algorithm using neural network. In AIP Conference Proceedings (Vol. 1967, No. 1, p. 040017) AIP Publishing LLC

[12] Zhang, S., Tang, T. and Liu, J., (2021) A Hazard Analysis Approach for the SOTIF in Intelligent Railway Driving Assistance Systems Using STPA and Complex Network. Applied Sciences, 11(16), p. 7714

[13] Amartuvshin D., Bilguunmaa M., Tadachika N., "Railroad Near-Miss Occurrence Detection and Risk Estimation System with Data from Camera Using Deep Learning", $5^{\text {th }}$ ICISPC IEEE conference, 2021

[14] https://smart2rail-project.net/, accessed on 24.10.2021

[15] https://www.railtech.com/innovation/2020/11/26/two-new-ato-researchprojects-launched-in-germany/?gdpr=accept

[16] Braband, J. and Schäbe, H., (2020) On Safety Assessment of Artificial Intelligence. arXiv preprint arXiv:2003.00260

[17] K Kurd, Z. and Kelly, T., (2003) September. Safety lifecycle for developing safety critical artificial neural networks. In International Conference on Computer Safety, Reliability, and Security (pp. 77-91) Springer, Berlin, Heidelberg

[18] Németh, A., Fischer, S. (2021) Investigation of the Glued Insulated Rail Joints Applied to CWR Tracks. Facta Universitatis, Series: Mechanical Engineering, doi: 10.22190/FUME210331040N 
[19] Directive (EU) 2016/797 of the European Parliament and of the Council of 11 May 2016 on the interoperability of the rail system within the European Union, http://data.europa.eu/eli/dir/2016/797/oj

[20] Directive (EU) 2016/798 of the European Parliament and of the Council of 11 May 2016 on railway safety, http://data.europa.eu/eli/dir/2016/798/oj

[21] El Koursi, E. M., Fletcher, S., Tordai, L. and Rodriguez, J., (2006) SAMNET Synthesis Report-Safety Management and Interoperability

[22] 2009/460/EC: Commission Decision of 5 June 2009 on the adoption of a common safety method for assessment of achievement of safety targets, as referred to in Article 6 of Directive 2004/49/EC of the European Parliament and of the Council (notified under document number C(2009) 4246)

[23] EN 50126 Railway applications standard - The specification and demonstration of Reliability, Availability, Maintainability and Safety (RAMS)

[24] Rail Delivery Group, “AWG Manual”, Sixth Edition, January 2018

[25] ERADIS - European Railway Agency Database of Interoperability and Safety, https://eradis.era.europa.eu/

[26] Sikkerhedsrapport for jernbanen 2019, Trafik-, Bygge- og Boligstyrelsen, København, September 2020

[27] Assessment of freight train derailment risk reduction measures Part A final report for ERA, Det Norske Veritas, July 2011

[28] Linardatos, P., Papastefanopoulos, V. and Kotsiantis, S., (2021) Explainable ai: A review of machine learning interpretability methods. Entropy, 23(1), p. 18 